\title{
Los sentidos en torno a las prácticas feriales de San Telmo y cómo operan en la configuración de diferentes colectivos
}

\author{
Andrea Jacqueline Gómez \\ Universidad Nacional de La Plata, Argentina \\ andreagomezperio@gmail.com \\ Leonardo Julio González \\ Universidad Nacional de La Plata, Argentina \\ leonardo.gonzalez@presi.unlp.edu.ar \\ Sebastián Novomisky \\ Universidad Nacional de La Plata, Argentina \\ sebastiann@perio.unlp.edu.ar
}

Recibido: 29/7/2018 / Aceptado: 10/1/2019

doi: 10.26439/contratexto2019.n031.3888

\begin{abstract}
Resumen. Concebimos las prácticas de la vida cotidiana en la ciudad como hechos comunicativos, a partir de entender a la comunicación como proceso de producción social de sentidos, como diálogo desde el cual se libran las luchas por el significado. En esta línea, el presente trabajo trata de reconocer los sentidos en torno a las prácticas feriales de San Telmo, ciudad de Buenos Aires, Argentina, y cómo operan en la configuración de diferentes grupos. Para ello nos posicionamos en un enfoque metodológico cualitativo de carácter etnográfico. Así, vemos que la constitución de los grupos se ve atravesada por las concepciones de legalidad e ilegalidad, las características de los feriantes, su lugar de origen, su relación con el espacio y cómo se producen tensiones y consensos que se entretejen e influyen en cómo pensar al otro, en una trama donde la cuestión del poder es central.
\end{abstract}

Palabras clave: comunicación / sentidos sociales / espacio público / ciudad / ferias 


\title{
Meanings around the San Telmo fair practices and how they operate in the configuration of different groups
}

\begin{abstract}
AвSTRACт. We conceive the practices of daily life in the city as communicative facts by understanding communication as a process of social production of meanings, as a dialogue from which struggles for meaning are fought. In this line, the present work tries to recognize the meanings around the San Telmo fair practices, city of Buenos Aires, Argentina, and how they operate in the configuration of different groups. For that purpose, we position ourselves from a qualitative ethnographic methodological approach. Thus, we see that the composition of the groups is influenced by the conceptions of legality and illegality, the characteristics of the traders, their place of origin, their relationship with space, and how tensions and consensuses that interweave with and influence how others think are produced in a plot where the question of power is central.
\end{abstract}

Keywords: communication / social meanings / public space / city / fairs 
E n las ferias de San Telmo, en Buenos Aires, conviven variados actores con diversas y desiguales posibilidades de ejercer un poder, adecuarse a él y proponer distintos usos del espacio público. A lo largo de la historia del barrio se han registrado diferentes procesos que afectaron a varios sectores, por los cuales el perfil de la zona y las ideas en torno al uso del espacio público han fluctuado en un estrecho vínculo con la coyuntura nacional y de la Ciudad de Buenos Aires.

En este sentido, Appugliese (2008) hace un recorrido histórico sobre los cambios ocurridos en el barrio de San Telmo, en relación a los distintos procesos que conllevaron a que los habitantes originales se trasladen hacia la periferia y lleguen nuevos actores, como los que la autora señala para el período 2001-2006. Estos aspectos también fueron evidenciados por Thomasz (2012), retomando los conceptos de establecidos y outsiders de Elias y Scotson (2000). El trabajo muestra cómo la apropiación del espacio público de San Telmo está sujeta a relaciones de poder, centrándose en cuatro grupos de actores: la Asamblea 20 de Diciembre, la Asociación de Anticuarios y Amigos de San Telmo, los vecinos establecidos y los recién llegados; en su relación con la Plaza Dorrego, el Mercado de San Telmo, el Parque Lezama y la calle Defensa (Thomasz, 2012).

No obstante, previamente a la crisis económica, política y social que sufrió la Argentina hacia fines del 2001, nuevos actores ya habían llegado al barrio. Entre ellos se encontraban los feriantes de Paseo Defensa, quienes inauguraron su emprendimiento en marzo del 2001. Luego se dividieron y pasaron a constituir dos ferias; la del Pasaje Giuffra -impulsada por la Asamblea 20 de Diciembrey la que continuó denominándose Paseo Defensa. Por esos mismos años también se hallaban feriantes en la zona de Montserrat; sin embargo, no fue hasta el 2011 que consiguieron algunos permisos temporarios para realizar su actividad. Por otro lado, algunos artesanos y revendedores que se encontraban sobre calle Defensa constituyeron una cooperativa el 2008, El Adoquín, como una forma de defender su espacio de trabajo ante las amenazas de desalojo por parte del Gobierno de la Ciudad. De esta forma, además de los grupos estudiados en los trabajos mencionados, observamos la constitución de distintos colectivos de feriantes con distintas características y diferentes grados de poder.

En esta línea, reconocer los sentidos en torno a las prácticas feriales y cómo operan en la configuración de diferentes grupos es de lo que trata este trabajo. Para esto nos planteamos indagar las relaciones de sentido en torno a las prácticas y el rol de los diferentes actores en la dinámica de las ferias; establecer los modos de operacionalización de las relaciones de poder que subyacen en la construcción de diversos colectivos; reconocer a través de qué dispositivos de inclusión /exclusión se manifiesta la diferenciación de los distintos grupos de actores; entender 
cómo se apropian del espacio público cada uno de estos e identificar qué procesos de solapamiento entre el espacio público y privado se pueden observar en las ferias de San Telmo.

En primer lugar, partimos de pensar a las prácticas sociales y de la vida cotidiana en la ciudad como hechos comunicativos, a partir de entender a la comunicación como proceso de producción social de sentidos, el cual transciende el ámbito de los medios para recuperar el sentido experiencial del término, como diálogo a partir del cual se libran las luchas por el significado. Para la realización de la investigación se partió de un territorio urbano: la calle Defensa y sus inmediaciones. Por tal motivo, para entender los procesos que aquí se producen fue importante repensar nociones sobre la ciudad en relación al espacio público.

Por su parte, González Sánchez (1983) explica que en la ciudad se modulan y modelan distintos significados relativos al espacio urbano. El bloque de clases que ejerce el poder de Estado posee esa competencia legítima. No obstante, eso no impide que los ciudadanos tengan sus propios significados de lo urbano. Por lo tanto, el sentido legítimo será el resultado de las luchas entre estos diferentes grupos, con desigual grado de poder y organización.

Aquí entra la disputa por el espacio público. Más aún cuando la ciudad experimenta el solapamiento de lo público y lo privado al son de la expansión del mercado. Sobre esta cuestión es operativo tomar los aportes de John Keane (retomado por García Canclini en su trabajo de 1997), a partir de los cuales se puede concebir a dichos espacios como un sistema modular de redes superpuestas, compuesto por esferas públicas de diferentes tamaños que interactúan entre sí y con los ámbitos privados, que las vuelven porosas, en forma de procesos de privatización y recomposición de la esfera pública, a través de dispositivos de inclusión y exclusión que organizan el espacio público.

En esta línea, Sergi Valera (1999) explica que la dicotomía espacios públicosespacios privados debiera entenderse más como un continuo sujeto al significado que los actores le dan al entorno. Esto implica pensar el espacio urbano como algo más que el escenario físico donde se desarrolla la vida de los sujetos, siendo un producto social que representa un conjunto de características que define a sus habitantes.

Aquí la apropiación del espacio, ya sea a través de la acción o de la identificación simbólica, es un doble proceso donde los sujetos se apropian del entorno transformándolo física o simbólicamente $\mathrm{y}$, al mismo tiempo, incorporan pensamientos, sentimientos o actitudes que los definen (Valera y Pol, 1994).

En un sentido similar, Rosana Reguillo Cruz (1996) plantea que la ciudad ya no puede concebirse como mero horizonte espacial sino como una gran red de comunicación que interpela a los actores de distintas formas. En ese espacio 
próximo "interesa la participación activa de los sujetos sociales en la construcción-apropiación del espacio, sujeta a múltiples mediaciones de carácter social, cultural y cognitivas" (Reguillo Cruz, 1996, p. 77).

Asimismo, la problematización de la ciudad puede ubicarse en el campo de la comunicación desde "el momento en que aparece la preocupación por las condiciones de reconocimiento, es decir cuando el actor de la comunicación deja de ser concebido como el circuito terminal del proceso comunicativo" (Reguillo Cruz, 1996, p. 80).

\section{Metodología}

Para la realización del trabajo nos posicionamos desde un enfoque metodológico cualitativo, de carácter etnográfico, con una perspectiva interpretativa, de diseño exploratorio. Para tales fines utilizamos herramientas como la entrevista semiestructurada y la observación participante. En una primera instancia se conversó con los actores de manera libre y posteriormente se focalizó en tres ejes: su mirada sobre sí mismos, sobre los otros y sobre el espacio público. Finalmente, los resultados fueron interpretados en relación al marco teórico, a partir de la construcción de distintas categorías de análisis: identidades, espacio público y relaciones de poder.

Ya en una primera instancia, a partir de la lectura de diferentes antecedentes, nos posicionamos desde la teoría fundamentada, es decir que fuimos al campo con categorías incipientes que podían fundamentarse y/o modificarse. Strauss y Corbin (2002) definen a esta teoría como la que deriva de datos recopilados de forma sistemática, analizados en el proceso de investigación. Por otro lado, partimos de una perspectiva sociosemiótica de la cultura, por lo cual el énfasis estuvo puesto en la significación y las opciones metodológicas apuntaron a la reconstrucción de la perspectiva de los actores sociales.

Así, se desarrolló un protocolo de la situación de entrevista con los actores y de la observación participante. Luego se eligieron los espacios donde se realizaron las entrevistas definitivas. Estos lugares fueron aquellos donde se encontraron variables o valores diferentes.

Los espacios correspondieron al corredor de ferias que se encuentra sobre calle Defensa, atravesada por Cochabamba, Avenida San Juan, Humberto Primo, Bethlem, Carlos Calvo, Estados Unidos, Pasaje Giuffra, Avenida Independencia, Pasaje San Lorenzo, Avenida Chile, México, Venezuela, Belgrano, Moreno, Alsina y Avenida Yrigoyen. A lo largo de este recorrido se encuentra Paseo Defensa (donde se vende material gráfico, artesanías y manualidades), la Feria de Antigüedades de Plaza Dorrego, las Ferias de las Artes I y II (dedicadas a fotografía y pintura) y la Feria del Pasaje Giuffra (artesanías y manualidades). Por 
su parte, la cooperativa El Adoquín, los feriantes de la zona de Montserrat y los vendedores que no están colectivizados se dedican a las artesanías, manualidades y reventa de productos industrializados. Así se pudieron especificar los ejes problemáticos y los matices existentes entre las diferentes localizaciones, lo que implicó la necesidad de incorporar a los vendedores de los locales de antigüedades que se ubican sobre calle Defensa.

En un primer momento, las unidades de análisis o sujetos de estudio fueron los feriantes; jóvenes, adultos y adultos mayores, hombres y mujeres, que todos los domingos ofrecen sus productos en las ferias autorizadas y no autorizadas por el Gobierno de la Ciudad de Buenos Aires. Además, aun cuando en una etapa preliminar no haya existido una delimitación premeditada, las unidades de análisis ya estaban "en la concepción del investigador, en los conceptos teóricos que emplea y en su objeto de investigación, pues se parte de ciertos conocimientos provisorios sobre el ámbito y los eventuales interlocutores" (Guber, 2004, p. 58). Estos serían los establecidos y los outsiders de los que hablan Elias y Scotson (2000), que hacen referencia a la estigmatización de determinados grupos a raíz de su tiempo de permanencia en el espacio urbano y de otras características, sujetos a relaciones de poder que son dinámicas. Por lo tanto y tras las primeras entrevistas fue necesario incorporar a más interlocutores, como los anticuarios de los locales y los representantes del Gobierno de la Ciudad.

Los muestreos estuvieron centrados en el proceso de investigación y no en sus resultados, por posicionarse desde una perspectiva cualitativa y ser de carácter exploratorio antes que conclusivo. Por eso, en esta línea, la elección del método implicó la utilización de técnicas flexibles de recolección de datos. Como ya se mencionó, los ejes de las entrevistas fueron su mirada sobre sí mismos, sobre los otros y sobre el espacio público. Así, a partir de las primeras categorías planteadas - relaciones de poder, espacio público e identidades - se observó su incidencia en el terreno y se incorporaron otras intermedias o emergentes, como lugar de pertenencia, de trabajo o resistencia, figura del Estado, figuras de referencia, prácticas permitidas y no permitidas, y legalidad o ilegalidad. En el desarrollo del proceso se apuntó a la saturación de las categorías y a determinar su capacidad significativa.

\section{Resultados}

\section{Los actores}

Para la realización de este trabajo se identificaron los diferentes actores de las ferias, con los que luego se realizaron las entrevistas semiestructuradas. Por un lado están los organismos del Estado que tienen una relación directa con los feriantes y se encargan de hacer cumplir la Ley 4121 (Gobierno de la Ciudad 
de Buenos Aires, 2012), que regula la actividad ferial. Estos son el ministerio de Cultura - a cargo del Museo de la Ciudad - y el ministerio de Ambiente y Espacio Público - donde se encuentra la Subsecretaria de Administración General y Uso del Espacio Público y dentro de esta la Dirección General de Ferias-.

Para comprender sus facultades es preciso retomar algunos aspectos sobre la Ley N. $^{\circ}$ 4121, que regula el funcionamiento de 30 ferias en toda la ciudad. La norma autoriza la venta de manualidades, la compra-venta y permuta de antigüedades, objetos de colección, de filatelia y numismática, revistas y libros usados, material fonográfico y videográfico que deben ser originales usados, reproducción de partituras musicales y material gráfico de colección.

Asimismo, la ley define el término "manualidad" como todo proceso mediante el cual se incorpora valor a los productos, siendo el mismo la aplicación de un esfuerzo personal al objeto que se comercializa. Además, prohíbe la actividad de reventa de artículos industrializados, a excepción de preservar las fuentes de trabajo de los vendedores de determinadas ferias, fuera de los barrios de San Telmo y Montserrat, para lo cual se debe acreditar el cumplimiento de ciertas reglas. En cuanto a la venta ambulante, esta no representa una infracción.

Dentro del territorio analizado, la ley autoriza los espacios de las Ferias de las Artes, Paseo Defensa, Pasaje Giuffra, Plaza Dorrego y calle Defensa del 100 al 600 inclusive. De esta manera no solo queda excluida la reventa sino también la venta de artesanías y manualidades de la cooperativa El Adoquín - de Avenida San Juan a Independencia - y los feriantes ubicados en Montserrat. Estos últimos solo han conseguido permisos temporales para algunos de sus miembros a partir del año 2011, pero aún no se ha fiscalizado la zona en un procedimiento integral.

Por otro lado, la Ley 4121 establece la figura de los delegados de las ferias, que serán elegidos por el voto secreto, obligatorio y directo de los feriantes. No obstante, en la reglamentación efectuada mediante el Decreto N. 079 del 2017, este artículo no fue tratado (Gobierno de la Ciudad de Buenos Aires, 2017). Asimismo, la ley determina la figura del armador, cuya actividad es el acarreo, armado, desarmado y conservación de las estructuras removibles que conforman el montaje de la feria, siendo quien provee o no dichos materiales. Estas personas deben estar inscritas en un registro público. Una posterior reglamentación determinaría cuál sería el mecanismo de selección de los armadores. Sin embargo, en el decreto del 2017 se menciona esta figura sin establecer aún el funcionamiento del registro y la modalidad de elección.

El Museo de la Ciudad es el ente encargado de aplicar la Ley 4121 en los espacios de la feria de antigüedades de la Plaza Dorrego y de las Ferias de las Artes I y II, ubicadas en calle Defensa al 100 y en Humberto Primo, lindante con la plaza. En cuanto al ministerio de Ambiente y la Subsecretaría de Uso del Espacio 
Público, estos se encargan del resto de las ferias de artesanías del Pasaje Giuffra y de calle Defensa, con excepción de las cuadras que corresponden a la feria de la Cooperativa El Adoquín y a los puesteros de la zona de Montserrat.

Por su parte, la Policía Metropolitana es la responsable de mantener el orden público. Puede realizar operativos de control y decomisar mercadería que no corresponda con la normativa y llevar adelante la detención de vendedores que incumplan la ley. En ocasiones se han producido episodios de violencia institucional. Un caso resonante fue el conflicto con los revendedores de Florida, en el año 2012, desalojados por parte del Gobierno de la Ciudad a través de la Unidad de Control del Espacio Público (UCEP), que se encuentra bajo la órbita del Ministerio de Ambiente y Espacio Público. Este tipo de hechos se replicaron en menor escala en San Telmo contra los feriantes de la cooperativa El Adoquín.

En cuanto a los vendedores de la feria de antigüedades de Plaza Dorrego, estos son adultos mayores, jubilados o pensionados que se procuran un ingreso adicional. La feria fue creada en 1970, impulsada por el Museo de la Ciudad, siendo la primera de la zona. Atraídos por la misma, entre fines de los años setenta y principios de los ochenta llegaron los anticuarios de los locales aledaños donde se venden artículos similares a los que se pueden ver en la plaza, aunque más costosos. Estos emprendimientos, que lograron persistir por sobre los comercios tradicionales del barrio, se encuentran, sin embargo, retrocediendo en favor de negocios de indumentaria, diseño y gastronomía.

A su vez, se encuentra la Asociación de Anticuarios y Amigos de San Telmo que también nuclea a comerciantes de diferentes rubros. Esta entidad está mayormente compuesta por los anticuarios de los locales del barrio y se dedica a promocionar su actividad comercial y realizar diferentes acciones en la zona de forma conjunta con organismos estatales como la Dirección General de Patrimonio, Museos y Casco Histórico.

Por otro lado se encuentra la feria del Pasaje Giuffra, dedicada a artesanías y manualidades, impulsada por la Asamblea 20 de Diciembre. Este último colectivo forma parte de Asambleas del Pueblo; una serie de organizaciones que se conformaron luego de la crisis económica, política y social de diciembre del 2001. Estos colectivos tienen como objetivo resolver distintas problemáticas que afectan a los vecinos en su zona de influencia, referidas a vivienda, alimentación, salud o educación. En San Telmo forjaron su identidad en torno a la figura de los primeros habitantes, que fueron esclavos, y al candombe como el género musical que le correspondía al barrio, en contraposición al tango, que es impulsado como patrimonio desde el Gobierno de la Ciudad.

Por su parte, otra de las ferias que nació en el contexto de la crisis del 2001 es Paseo Defensa, una iniciativa de vecinos y comerciantes del barrio, ubicada sobre 
la calle del mismo nombre, entre Cochabamba y avenida San Juan. El Paseo se encuentra dividido en diferentes espacios. Entre ellos, la Feria Gráfica está vinculada a distintas organizaciones; se ha unido a la Asociación de Anticuarios y Amigos de San Telmo e impulsa diversos emprendimientos solidarios en el barrio. Asimismo, en la misma cuadra se encuentra la Cooperativa Artesanos de Argentina. Sus miembros alquilan dos locales y algunos también poseen un puesto en la feria de la calle. A su vez, también forman parte de la Asociación de Anticuarios y Amigos de San Telmo.

Continuando el recorrido, en las cuadras comprendidas entre las avenidas San Juan e Independencia se encuentra la feria de El Adoquín, una cooperativa integrante de la Confederación de Trabajadores de la Economía Popular (CTEP). Aquí se ubican artesanos, manualistas y algunos revendedores. Esta feria no tiene autorización del Gobierno y en algunas oportunidades se han producido desalojos y hechos de violencia institucional. Sin embargo, identificados por feriantes, comerciantes y frentistas con el nombre de manteros, los miembros de la cooperativa se reconocen como trabajadores y luchan por permanecer en el espacio.

Asimismo, se encuentra el sector ferial de la zona de Montserrat que incluye a artesanos, manualistas y revendedores, considerados por parte de algunos interlocutores como una competencia desleal para los comercios de la zona. Este último aspecto es uno de los argumentos de los comerciantes de los locales, según los cuales los vendedores de la calle no pagan impuestos y por ende, pueden vender más barato que ellos.

Por otro lado, un actor particular es el referente de cuadra, que se constituye como delegado a partir de haber impulsado la feria o por características de su personalidad. En determinadas ferias, este rol lo ocupan los armadores que alquilan las estructuras de los puestos, quienes mediante el pago de un canon otorgan un espacio de la calle a los feriantes, un aspecto que ha sido definido como coactivo por algunos interlocutores.

Otros actores son los artistas que mayormente se encuentran en la cuadra ubicada sobre Defensa, entre avenida San Juan y Humberto Primo. Por otro lado, además de la oferta gastronómica de los locales, se encuentran los vendedores de alimentos que tienen su punto fijo en la Plaza Dorrego o en la calle, sumados a los ambulantes que en su mayoría son jóvenes estudiantes latinoamericanos.

Por otra parte se encuentran los vecinos. Los que se ubican sobre la calle Defensa, por lo general no estaban satisfechos con la llegada de los emprendimientos feriales. Con el tiempo y las normas de convivencia discutidas por los mismos feriantes, algunos residentes se mostraron conformes debido a que antes de las ferias el barrio se encontraba, según relatan, un tanto abandonado y peligroso. 
Entre los habitantes del barrio algunos son propietarios o inquilinos, extranjeros que se encuentran por un tiempo en el país y también personas que ocupan antiguas casonas en forma ilegal, aunque esta última situación disminuyó en los últimos años. A su vez, como señala Appugliese (2008), se encuentran aquellos actores vinculados al campo del arte y el diseño que han decidido afincarse y desarrollar su actividad. Por su parte, también se pueden apreciar rivalidades entre los residentes más antiguos y los recién llegados, por tener distintas concepciones sobre el uso del espacio público y la observancia de normas de urbanidad tácitas, como advierte Thomasz (2012).

\section{Los sentidos en torno a las prácticas feriales de San Telmo}

Por un lado vemos cómo los vínculos interpersonales, la camaradería, las ganas de ayudar - que se proyectan en diferentes emprendimientos solidarios de la zona- o las rivalidades están presentes en el desarrollo de las relaciones que dan lugar al rearmado de diferentes grupos, según formas de actuar comunes que van a estar ligadas a la actividad de los actores y las ideas compartidas, las formas de mirar al otro y pensarse a sí mismos.

Por su parte, va a tener incidencia el papel o rol de los actores en la dinámica de las ferias. Por ejemplo, revender productos industrializados, antigüedades, artesanías o manualidades va a conllevar distintas apreciaciones de parte de los propios protagonistas y de quienes los observan. Sobre este punto se suscitan diferencias, opiniones contrapuestas pero también una mirada superadora por parte de algunos grupos, como en el caso de la cooperativa El Adoquín -compuesta por artesanos, manualistas y revendedores-, donde consideran que al modificarse el mundo del trabajo, la identidad del trabajador también se transforma y complejiza. Así, hasta que incorpora su nueva situación de clase, puede empezar revendiendo para luego comenzar con la fabricación.

De esta manera, si bien existe la diferenciación entre feriantes legales e ilegales en términos formales, todos ellos se sienten legítimos. A su vez, encontramos diferentes agrupamientos según el tipo de producto que venden. También tenemos los que se encuentran de manera estable o en calidad de visitantes. Sin embargo, lo que los hace a todos iguales es su condición de trabajadores.

Por ejemplo un referente del sector ferial de la zona de Montserrat nos habló sobre los revendedores de manera conciliadora, como quienes tienen derecho al trabajo, en relación a la propuesta que se les ha hecho desde el Gobierno de la Ciudad para que se conviertan en manualistas.

Lo que se logró es, sobre el producto, ponerle mano de obra. Por ejemplo, vos comprás una estatuita de bailarines de tango y la pintás a mano... Tenemos que 
tener en cuenta que somos individuos. Cada uno hace lo que sabe. No porque cada uno haga lo que sepa, o lo que puede, se va a castigar con la misma vara a todos. (Referente de Montserrat, comunicación personal, 12 de febrero del 2017)

De esta forma vemos cómo el tipo de actividad, que en ocasiones delimita diferentes subgrupos dentro de los trabajadores, también puede ser percibido como un continuo, una necesidad y un derecho, como también manifiestan desde la cooperativa El Adoquín.

Por otra parte, el verse a sí mismos como trabajadores y su relación con el espacio es una consideración más o menos compleja según cada feria. Desde la cooperativa El Adoquín, miembro de la Confederación de Trabajadores de la Economía Popular, el espacio público es concebido como punto final de la cadena productiva y su identidad está relacionada al trabajo individual, colectivo y a las reivindicaciones gremiales.

En El Adoquín, el trabajo en la calle se vuelve lícito los domingos cuando las leyes se subvierten, en un ánimo que remite a las fiestas, los carnavales o aquellas ferias cuyo componente lúdico es preponderante sobre el comercial. Este es un aspecto que está presente en todas las ferias, si bien los integrantes de la cooperativa se manifiestan como un colectivo organizado que maneja cierta terminología, teorías o conceptos particulares como el de "cadena productiva" o las referencias al carnaval.

Por otro lado, en oposición a los feriantes se encuentran algunos anticuarios de locales aledaños que atribuyen la baja de sus ventas a la presencia de los vendedores; consideran que obstruyen la circulación, ensucian o son problemáticos.

Tener gente todo el día delante de tu negocio, la primera vez te puede parecer simpático. Ya después no. Gente sentada, comiendo, que deja todo sucio. Los lunes no te das una idea de lo que es. Todo sucio. Hasta te podés encontrar con gente que hace necesidades en la calle. Te encontrás de todo. Los domingos es todo lindo, todo limpio. ¿Pero lo que dejan para el lunes? Yo saco botellas vacías, rotas, papeles y demás. Antes cerrábamos a las siete de la tarde. Hoy ya a las cuatro nos vamos. (Anticuario de San Telmo, comunicación personal, 29 de enero del 2017)

En esta línea, la Asociación Anticuarios y Amigos de San Telmo ha presionado a las autoridades gubernamentales para que erradique a los feriantes. Sin embargo, también existen anticuarios que tienen una mirada positiva sobre las ferias:

La feria es buena porque atrae gente. Es un paseo donde pasan y pueden ver lo que hay. Antes, que solo era la plaza, esas personas no llegaban acá. No venían a mirar porque estaba todo vacío. (Anticuario de Montserrat, comunicación personal, 12 de febrero del 2017) 
Además, representantes del Estado manifiestan su posición a través de discursos que guardan relación con la opinión que algunos anticuarios e integrantes de las ferias autorizadas tienen sobre los sectores que se encuentran fuera de la norma. Así, encontramos tópicos que se reiteran, como la pérdida del orden, el perjuicio que los revendedores traerían a diferentes grupos, el derecho legítimo al espacio, entre otros. En esta línea se observan referencias a la ilegalidad y al delito como ideas vinculadas a los revendedores, denominados como manteros.

Así vemos cómo se atribuyen ciertas características a un determinado grupo, como también advertimos en las entrevistas con los anticuarios de locales aledaños. Además observamos que, pese a que algunos grupos de artesanos y manualistas se encuentran en una situación económica similar a la de los llamados manteros, reproducen discursos contra la reventa en el espacio público. Los argumentos pueden variar, como por ejemplo el derecho al espacio que les daría el pago de un canon, la permanencia o por ser los primeros en ocuparlo. "Yo, habiendo trabajado y aportado, cobro la mínima de jubilación, razón por la cual tengo que seguir trabajando... No pagan un puesto como lo pagamos nosotros. Pagamos el puesto. No estamos gratis" (artesana del Pasaje Giuffra, comunicación personal, 5 de febrero del 2017).

Una situación particular es la de los vendedores de productos industrializados que son inmigrantes latinoamericanos de países limítrofes, los cuales constituyen un número pequeño en relación a la cantidad total de feriantes. Algunos anticuarios y artesanos asocian a los revendedores inmigrantes con la vagancia, el conflicto, la delincuencia o las "mafias". Como contrapartida están los sentidos en torno a los argentinos de presunta ascendencia europea: aquellos que poseen la legitimidad para estar en la feria.

Me indigna que ni siquiera son argentinos. Ni siquiera está trabajando un argentino. Vienen, les arman los puestos... Qué lindo es Buenos Aires, los edificios, de nuestra inmigración, que realmente venía a laburar. Los españoles, los italianos, los franceses, los alemanes que vinieron acá realmente a trabajar. (Anticuaria de San Telmo, comunicación personal, 29 de enero del 2017)

Por otra parte, la autoridad de aplicación de la Ley 4121 considera al Estado desde la visión de una democracia delegativa, en relación a los controles que este efectúa y en contraposición a las decisiones y acciones que algunos feriantes realizan por sí mismos.

Los vendedores organizados, como los de la Asamblea 20 de Diciembre - encargada de la Feria del Pasaje Giuffra- o la cooperativa El Adoquín, son formas de gestión que constituyen una oposición al sistema de referentes usual en el resto de las ferias. Se trata de organizaciones que toman las 
decisiones colectivamente aunque tienen sus figuras de referencia. Asimismo, están los feriantes que no están agremiados y que se manifiestan en contra de esta modalidad.

Nosotros acá hablamos con gente que viene de partidos políticos, organizaciones sindicales, sindicatos de vendedores de la calle. Y todos quieren sacar su parte, su tajada política y su beneficio... Por ahí te vas a encontrar con cuadras donde no hay delegados, no hay referentes, porque hay luchas de algún tipo, porque hay un sindicato que tiene que mandar. (Referente de Montserrat, comunicación personal, 12 de febrero del 2017)

Por su parte, el Gobierno de la Ciudad se manifiesta en pro de la figura del Estado representativo; reclama que las organizaciones sociales mencionadas han cobrado un nivel de poder que les permite realizar negociaciones con el Estado y que, por el contrario, el pueblo debe acatar las decisiones de sus representantes.

\section{Las figuras de referencia}

Por otro lado, la constitución de cada sector ferial se ve atravesada por determinados actores que les otorgan sentido de conjunto, a modo de líderes de opinión. Estos son quienes se definen como referentes o delegados. Se trata de actores que por impulsar la actividad, características de su personalidad o por mostrar idoneidad en algún momento puntual, se transforman en una figura de protección o apoyo para los demás, organizan el espacio público y establecen reglas de convivencia, sin por eso estar exentos de rivalidades y conflictos. Así tenemos por un lado a la autoridad formal, como el Museo de la Ciudad o el ministerio de Ambiente y Espacio Público, y a otra informal. Además, también se encuentran algunos feriantes que no son pensados como líderes, pero que en determinados momentos adquieren un grado de colaboradores, a partir de una participación muy activa, su carácter o trayectoria.

Las decisiones tomadas por los referentes se comunican al resto de los feriantes desde una estructura vertical, salvo en ciertas ferias que tienen otro tipo de organización. A su vez, el Gobierno respalda este sistema de delegados por cuadra como sus mediadores, pero estos reclaman un sistema de votación formal, situación que se vuelve más apremiante en las cuadras donde existen varias figuras de referencia que suelen entrar en conflicto por plantear ideas diferentes. “Está complicado porque cada uno tiene intereses distintos a defender, y eso creo que es lo que nos va separando y no podemos lograr representación por cuadra" (artesana de Montserrat, comunicación personal, 12 de febrero del 2017).

También puede ocurrir que los armadores sean referentes de cuadra o colaboradores, suscitando críticas por ser los que alquilan los puestos, hecho considerado como un acto de coacción por parte de algunos feriantes. 
Terminan organizando los armadores, lo que también termina siendo una forma de coacción: "Si vos no me pagás lo que yo te pido, no te doy el lugar". O sea, todos lucran. O con el espacio público o con la necesidad de trabajo ajena. (Artesana de Montserrat, comunicación personal, 12 de febrero del 2017)

Por su parte, en el sector de El Adoquín no se paga un canon sino que el permiso para armar un puesto se gestiona en la relación con los referentes, lo que también puede constituir una situación más o menos compleja según diferentes interlocutores.

Hay gente que es muy copada, gente neutral y gente con la que uno puede llegar a tener conflictos. De pronto sí se siente un poco de mala onda. No en estos espacios, sino en los que son libres. En los espacios libres es más difícil hacerse un lugar. Entonces la territorialidad hace que se den este tipo de situaciones que pueden ser incómodas. (Artesano del Pasaje Giuffra, comunicación personal, 5 de febrero del 2017)

Por otro lado pudimos observar cómo los conflictos se producen en una relación dinámica con los consensos, a partir de diferentes situaciones que nos permitieron comprender que siempre se encuentran en disputa los sentidos en torno al uso del espacio público, junto a otros aspectos asociados, como el trabajo y la legalidad/ilegalidad. Así, analizamos qué sucede entre las diferentes partes existentes, cuáles son los motivos de discrepancia y cómo son sus relaciones.

\section{El conflicto con el Gobierno de la Ciudad}

Luego de la crisis de 2001, la figura del Estado a nivel nacional se encontraba devastada, excediendo la jurisdicción de la Ciudad de Buenos Aires. Tener en cuenta este retroceso en el momento en que surgen las ferias permite trazar la historia colectiva, las narrativas y las biografías comunes, donde son importantes las relaciones con el otro tanto en ese pasado como en el presente. En ese contexto, la realidad de muchas familias fue buscar formas de subsistencia por fuera de las alternativas tradicionales. Así, por circunstancias de la coyuntura en una época determinada vemos cómo se empoderan algunos colectivos como las asambleas vecinales y asociaciones que desarrollan diferentes emprendimientos en el barrio, entre los que se encuentran las ferias.

Actualmente la Ley 4121 solo autoriza algunos sectores (Gobierno de la Ciudad de Buenos Aires, 2012; 2017). Sin embargo los feriantes resisten con mayor o menor grado de organización a los intentos de expulsión que se producen tanto desde lo material como desde lo discursivo. Por ejemplo, a nivel del discurso observamos diferentes situaciones como la estigmatización de los feriantes según sus características y en relación al uso que hacen del espacio 
público. En este sentido, como ya se ha mencionado, encontramos discursos de representantes del Estado sobre el uso que debiera tener la calle y su concepción sobre lo que implica un gobierno representativo y una democracia delegativa frente a otras formas de organización de las cuales participan los feriantes.

Por su parte, vemos cómo la legalidad de la actividad diferencia a unos grupos de otros en una relación con el Gobierno más o menos conflictiva. Así se puede observar una diferenciación entre los grupos que están legitimados por el Estado - las ferias autorizadas-, con respecto a los otros, y también entre quienes luchan por ese reconocimiento a través de la toma del espacio público.

Por otro lado, observamos cómo la figura de los referentes contribuye a la constitución de distintos grupos que se aglutinan alrededor de estas personas. No obstante, el conjunto reclama que se establezca un modo de elección formal de los delegados, además de una modalidad de otorgar permisos que reconozca a aquellos feriantes con más antigüedad en la zona y que no beneficie a los recién llegados. En las quejas sobre estos puntos existe un consenso acerca de la figura del Gobierno como quien tiene la obligación de ordenar el espacio público: "Se necesita que el Estado intervenga. Hasta ahora la intervención no es la más adecuada porque hay toda gente nueva sin experiencia" (artesana de Montserrat, comunicación personal, 12 de febrero del 2017). "Del tema de reventa no somos nosotros los que nos tenemos que ocupar. Se tiene que ocupar el Gobierno de la Ciudad... Acá el Gobierno es el que tiene el poder" (artesana de San Telmo, comunicación personal, 29 de enero del 2017).

\section{Instancias de acuerdo}

No obstante, podemos observar instancias de acuerdo que están presentes de la misma manera que lo están los conflictos. Así, advertimos cómo entre los diferentes grupos de feriantes o con los demás actores del barrio se da una convivencia más o menos armónica. Por ejemplo, los feriantes de las distintas cuadras pueden mantener relaciones temporarias para ir juntos a realizar trámites en la Dirección de Ferias. Asimismo, algunos comerciantes, incluidos anticuarios, consideran la presencia de las ferias como un beneficio. "Esto lo hace pintoresco. Así las personas ven que hay cosas por las que venir para este lado" (anticuario de Montserrat, comunicación personal, 12 de febrero del 2017).

\section{Dispositivos de inclusión /exclusión}

Por su parte, la existencia de distintos colectivos está vinculada a diferentes dispositivos de inclusión/exclusión de expresión material y simbólica, como por ejemplo el tiempo de permanencia en el espacio, con autorización del Gobierno o sin ella. En este sentido, los permisos que otorga el Estado para estar en el espacio 
público y tener el puesto fiscalizado con un cartel del Gobierno de la Ciudad, diferencian a los feriantes que los tienen de los que no.

Una situación similar se da entre los feriantes y los armadores de los puestos a través del pago de un canon mensual que es lo que permite la apropiación de un lugar en la calle. Los armadores o la organización de una feria como en el caso del Pasaje Giuffra, toman estos espacios en una primera instancia y los ceden a los feriantes que pagan el canon.

Por otro lado se encuentran dispositivos de inclusión/exclusión que tienen que ver con los discursos en relación a los revendedores inmigrantes y/o nativos argentinos frente a los de ascendencia europea. Sobre los primeros, algunos anticuarios y artesanos los califican como personas que ensucian el espacio, delinquen o conforman "mafias", refiriendo que los vendedores son "empleados" de terceros que gestionan varios puestos a la vez, constituyendo una especie de organización donde la mercadería puede tener un origen ilegal. “Te estás metiendo con mafias, con un montón de cosas. Vos podés venir acá y vas a ver los mismos artículos, la reventa, en varios lugares. $\mathrm{Y}$ todo eso pertenece a uno que es una organización con empleados" (artesano de Montserrat, comunicación personal, 12 de febrero del 2017).

\section{Apropiación del espacio público}

Hemos visto cómo las distintas formas de apropiación del espacio tienen un papel importante en la definición de los diferentes grupos. En este sentido observamos modos de apropiación de la calle como lugar de trabajo, de pertenencia y de resistencia.

Como ya se ha mencionado, para todos los feriantes la calle es su lugar de trabajo, tanto para los que están autorizados como para los que no. Para estos últimos es un espacio de resistencia y lucha frente al desempleo y a las autoridades que intentan desalojarlos.

También es un territorio apropiado material y simbólicamente por aquellos que tienen un apego a las ferias o al barrio donde se establecen diferentes tipos de vínculos. Así, se pueden establecer dos formas de realizar lo que podríamos llamar un aporte al barrio. Una nace en el hacer de la propia feria, con un carácter más espontáneo que organizado, que provee mejoras vinculadas a la seguridad o el ordenamiento urbano. De esta forma, con la presencia de los artesanos urbanos de Paseo Defensa o los de Montserrat, se transformó un espacio que algunos sectores calificaron como peligroso. "Cuando nosotros vinimos acá esto era un desastre. El barrio era denso, era pesado. Los vecinos nos agradecen toda la vida, porque gracias a que nosotros estamos acá esto cambió" (artesano de Paseo Defensa, comunicación personal, 22 de enero del 2017). 
Por otro lado está el trabajo solidario que se ejerce de forma programada desde una serie de organizaciones y que, muchas veces, sobrepasa a las ferias y comprende a todo el barrio y zonas aledañas.

Tenemos un comedor comunitario para la gente de la calle que funciona de lunes a sábados y un merendero para chicos que funciona de lunes a viernes. Con la venta de las películas, los libros, las remeras, más una ayuda que nos da el Gobierno de la Ciudad, subsiste el comedor. Aparte, tenemos un emprendimiento gastronómico que también funciona para gente de trabajo. Se le da de comer a la gente un menú fijo. Después tenemos dos centros culturales. En el Centro Cultural Rosa Luxemburgo funciona librería y teatro. Después tenemos otro centro cultural en la calle Paseo Colón. Es un teatro que se llama Ceverino Di Giovanni y está apadrinado por Osvaldo Bayer. (Referente del Pasaje Giuffra, comunicación personal, 5 de febrero del 2017)

Tenemos un club de futbol para chicos y la primera orquesta-escuela de San Telmo para jóvenes, ambos gratuitos. Funcionan en la Fundación Mercedes Sosa. Estos dos espacios van a empezar a promoverse dentro de la intersectorial como espacios sociales, que contemplan el desarrollo de los jóvenes y chicos de San Telmo. La idea es que no solo tratemos cosas comerciales, culturales o turísticas. San Telmo es un barrio y tiene problemas sociales también. (Referente de Paseo Defensa, comunicación personal, 22 de enero del 2017)

Asimismo, en cuanto a la apropiación del espacio, observamos una situación particular. "La feria de San Telmo" - en singular y sin hacer alusión a sus diferentes sectores y colectivos- es reconocida por su nombre como una de las más populares del mundo. La zona perimetral del barrio está entre Avenida Caseros y calle Chile, y luego continúa el barrio de Monserrat. Esta definición delimita distintos sectores barriales pero no implica una división en las ferias.

Estamos en Montserrat. Estamos continuados. La feria va desde donde termina la Plaza Dorrego hasta Plaza de Mayo. Además, si no laburás acá, sos vecino o investigás, los demás no saben que esto no es San Telmo. Para ellos somos lo mismo porque somos lo mismo en otro barrio. (Revendedor de Montserrat, comunicación personal, 12 de febrero del 2017)

\section{Solapamiento entre el espacio público y el privado}

Los conceptos de espacio público y privado se solapan cuando se piensa al territorio de ambos modos, según cuáles sean las prácticas y quiénes los que las desarrollan. En relación con esto observamos la diferenciación entre prácticas permitidas - transitar, mirar- y no permitidas -instalarse, vender o revender - que generan la señalización o estigmatización de quienes las realizan. Así tenemos que algunos actores consideran que el espacio público ha sido privatizado por los artesanos, manualistas y revendedores. 
Además, ante la apropiación del espacio por parte de los feriantes se produce la misma práctica pero por parte de los anticuarios de los locales, que también interponen diferentes objetos para que los vendedores no coloquen sus sillas, cajas $u$ otros elementos.

Yo llego, saco una mesita frente a mi local y pongo cosas para que la gente vea que eso que está viendo es del local. Y así puedan entrar. Si vengo y no pongo nada vienen los muchachos y me venden pulóveres en frente de mi puerta. Me tapan, las personas ven menos lo que tengo para ofrecer y no me sirve. (Anticuario de Montserrat, comunicación personal, 12 de febrero del 2017)

Tenemos que venir más temprano para ocupar nuestro lugar, por el cual pagamos impuestos, para que no nos invadan. $\mathrm{Y}$ esos arbolitos de adorno, que nosotros compramos para poner en la vereda, la Municipalidad nos los hace entrar o poner sobre el escalón, porque la vereda no se puede ocupar los días de semana. ¿Mirá lo que es el domingo? (Anticuario de San Telmo, comunicación personal, 29 de enero del 2017)

\section{Discusión}

Actualmente el conflicto por el uso del espacio público en San Telmo continúa. La reglamentación de la Ley 4121 de 2017 no ha tratado puntos importantes que los vendedores de las ferias reclaman: un sistema de elección de delegados y una modalidad de otorgamiento de los permisos que respete a los feriantes con más antigüedad en la zona. Por su parte, pese a las reiteradas reuniones que tienen los miembros de El Adoquín con los representantes del Ministerio de Ambiente, no han llegado a un acuerdo sobre su presencia en la calle. El decomiso de mercadería sigue sucediendo tanto en las ferias de San Telmo como en otros barrios de la ciudad de Buenos Aires.

El Gobierno de la Ciudad se hace presente de forma esporádica con censos y acciones violentas. En relación a esto, se reproducen sentidos vinculados a la inoperancia y la injusticia. El Estado se encuentra así, de forma material y simbólica, como una autoridad que, pese a las críticas sobre su desempeño, ha sido internalizada por los feriantes y se renueva en los momentos de conflicto: una figura omnipresente a través de la ley, que tiene la capacidad y obligación de ordenar el espacio público. Así, en el derrotero de las luchas entre estos distintos grupos, con desigual grado de poder y organización, el Estado sigue conservando su carácter de garante del orden público y, retomando a González Sánchez (1983), de la competencia legítima en la construcción de sentidos sobre el espacio urbano que se modulan y modelan en la ciudad a pesar de la existencia de los significados propios de los sectores subalternos. 
Así, el Gobierno aparece en escena como quien, a través de sus representantes, reproduce o resignifica sentidos estigmatizantes asociados a las prácticas feriales, lo que también ocurre por parte de algunos sectores de feriantes y anticuarios de los locales.

En este contexto, la constitución de los diferentes grupos se ve atravesada por las concepciones de legalidad e ilegalidad, las características de los feriantes, su lugar de origen, su tiempo de permanencia en el espacio público, su relación con él y cómo - con el territorio en disputa- se producen tensiones y consensos que, retomando a Elias y Scotson (2000), se entretejen e influyen en cómo pensar al otro, en el marco de relaciones de poder que son dinámicas.

En esta línea, el solapamiento entre la concepción del espacio como público y privado tiene vinculación con las prácticas permitidas y no permitidas, y con la estigmatización que conlleva a los grupos que realizan estas últimas. En este sentido, el que privatiza el espacio siempre será el otro.

Como plantea John Keane (retomado por García Canclini en su trabajo de 1997), se puede pensar al espacio público como un sistema de redes superpuestas, que interactúan entre sí y con los espacios privados. O un continuo sujeto a la significación que le den los sujetos (Valera, 1999). Aquí entran en juego dispositivos de inclusión/exclusión materiales y simbólicos, como el tiempo de permanencia en el espacio, el cartel del Gobierno de la Ciudad que muestran los feriantes autorizados, el pago de impuestos o la decoración y artículos elegantes con los que algunos anticuarios de los locales - un sector socioeconómicamente privilegiado- ocupan la vereda o la calle.

A estas diferenciaciones entre los colectivos se suman otras vinculadas a las formas de apropiación del espacio, por ejemplo, como lugar de pertenencia, de trabajo y de resistencia. Pues el entorno urbano es un espacio de comunicación donde los ciudadanos intervienen en su realidad, hecho sujeto a múltiples mediaciones (Reguillo Cruz, 1996), transformando física o simbólicamente el espacio, y, en ese proceso, incorporando sentimientos y actitudes que los definen (Valera y Pol, 1994).

Por su parte, si bien la apropiación del espacio es común a todos los colectivos en distintos grados, se pueden hacer algunas consideraciones. Un caso particular es el de los vendedores del barrio de Montserrat, que se consideran parte del corredor de ferias de San Telmo. Valera y Pol (1994) se refieren a la definición de los límites territoriales que juegan un papel importante en las relaciones entre los grupos y su constitución. Sobre la categoría barrio, expresan que "los grupos tienden a definir sus propios límites que, en muchos casos, no coinciden totalmente con los administrativos [...]. La delimitación territorial resulta una construcción social comúnmente elaborada y compartida" (Valera y Pol, 1994, p. 18). 
El sentido de pertenencia a las ferias en particular y al barrio en general se evidencia fuertemente en aquellos grupos que participan de actividades solidarias, como la feria gráfica de Paseo Defensa o la del Pasaje Giuffra, que se encuentran contenidas dentro de organizaciones más grandes.

Por su parte, la identidad como trabajadores y la resistencia en el espacio son aspectos que pueden apreciarse fuertemente en los grupos más organizados, como la cooperativa El Adoquín, a partir del manejo de conceptos que tienen que ver con diferentes aspectos, como las trayectorias de sus miembros en relación con el grupo y sus reivindicaciones gremiales.

Estas características los oponen al Estado y al resto de los feriantes. Vemos el enfrentamiento de la imagen del feriante en apariencia independiente a la actividad política, que solo asiste a la feria por su necesidad de trabajo y se ciñe a un modelo de representación por cuadra alentado por el propio Gobierno - que planea instaurar un sistema de elección de delegados - frente a una forma distinta propuesta desde el interior de espacios con otros modos de participación y acción, donde en teoría se toman las decisiones colectivamente mediante formas como las asambleas. De esta manera, aún se siguen desconociendo estos otros modos de acción política, junto a la apropiación del espacio público y la constitución de economías alternativas.

Sin embargo, mientras no se lleve a cabo el desplazamiento de las ferias no autorizadas o de otras prácticas culturales efectuadas en el espacio público, se puede hablar de un consenso, siempre precario y amenazado por la posibilidad de una orden de desalojo o actos de violencia institucional.

Así las cosas, los nuevos conflictos por la reventa, tanto en San Telmo como en otras zonas de la ciudad de Buenos Aires, vuelven a actualizar la necesidad de llegar a acuerdos a partir de la constitución de espacios de diálogo. La participación ciudadana, la autonomía e interdependencia entre los diferentes espacios y actores involucrados puede aportar a la resolución de los conflictos y el crecimiento de sus proyectos. Estas soluciones deben venir de los propios actores, con respeto a sus deseos y a sus identidades, reconociendo la voz de aquellos que han sido hablados por otros.

\section{Referencias}

Appugliese, S. L. (2008). La planificación urbana en relación con el acceso a la ciudad. Question. Revista Especializada en Periodismo y Comunicación, 1(20). Recuperado de http://perio.unlp.edu.ar/ojs/index.php/question/article/view/686/589

Elias, N. y Scotson, J. (2000). Os establecidos e os outsiders. Rio de Janeiro: J. Zahar. 
García Canclini, N. (1997). Zonas de indecisión entre lo público y lo privado. La Plata: Ediciones de Periodismo y Comunicación.

Gobierno de la Ciudad de Buenos Aires. Ley N. 4121 - Actividades feriales. (10 de febrero del 2012). Boletín Oficial del Gobierno de la Ciudad de Buenos Aires, 3852. Recuperado de http://www2.cedom.gov.ar/es/legislacion/normas/ leyes/ley4121.html

Gobierno de la Ciudad de Buenos Aires (23 de febrero del 2017). Reglamentación Ley 4121 - Actividades Feriales. Decreto $N^{\circ}$ 079/017. Boletín Oficial del Gobierno de la Ciudad de Buenos Aires, 5076. Recuperado de http://www2. cedom.gov.ar/es/legislacion/normas/leyes/anexos/drl4121.html

González Sánchez, J. A. (1983). Frentes culturales urbanos. Notas varias sobre la construcción de la hegemonía en la ciudad: a medio camino entre el pavimento y el smog. Iztapalapa, Revista de Ciencias Sociales y Humanidades, 5(9), pp. 79-86.

Guber, R. (2004). El salvaje metropolitano. Reconstrucción del conocimiento social en el trabajo de campo. Buenos Aires: Paidós.

Reguillo Cruz, R. (1996). Tejido social. Cambio en la continuidad. En La construcción simbólica de la ciudad. Sociedad, desastre y comunicación. México: ITESO/Universidad Iberoamericana.

Strauss, A. y Corbin, J. (2002). Bases de la investigación cualitativa. Técnicas y procedimientos para desarrollar la teoría fundamentada. Medellín: Editorial Universidad de Antioquia.

Thomasz, A. G. (2012). De establecidos y outsiders en el centro histórico de la Ciudad de Buenos Aires. Papeles de Trabajo, 24 (diciembre, 2012). Recuperado de http://www.scielo.org.ar/pdf/paptra/n24/n24a05.pdf

Valera, S. (1999). Espacio privado, espacio público: Dialécticas urbanas y construcción de significados. Tres al Cuarto, 6, 1999, pp. 22-24. Recuperado de http://www.ub.edu/escult/editions/0tresal.pdf

Valera, S., y Pol, E. (1994). El concepto de identidad social urbana: una aproximación entre la psicología social y la psicología ambiental. Anuario de Psicología, 62, pp. 5-24. Recuperado de http://www.ub.edu/escult/editions/0identidad.pdf 
